\title{
Greek Womens' Mentality towards Fashion Brands and the Influence of Print Images
}

\begin{abstract}
By Ekaterini Drosou*
This paper presents the findings on Greek women's viewpoints and opinions in regards to foreign fashion brands and the symbolic meanings they attach to them. Further, a greater and wider knowledge was desired on the effects of fashion magazine brand advertising in the formation to the views and symbolisms formed, through the adoption of a symbolic interactionist framework. Additionally, a greater understanding on the communication process between Greek women and fashion brands advertised in fashion magazines was also of interest, assisting in comprehending Greek women's interpretation of print images and how these images influence fashion brand symbolism. This research provides an understanding towards the general mentality of Greek women towards foreign fashion brands, how they attach meanings to those brands and what influences this process.
\end{abstract}

Keywords: Greek, Foreign Fashion Brands, Symbolism, Meaning.

\section{Introduction}

The Greek market appears to be neglected in consumer identity studies compared to other markets such as the American and British (Karanika and Hogg 2010). The Greek female consumer is an underexplored social group, resulting in a great lack of knowledge in regards to the symbolisms and meanings foreign fashion brands have for them.

This presented a need to achieve a greater understanding on the socially shared meanings and interpretations Greek women give to fashion brands, while adding to an understanding of symbolic consumption as a socially rooted process. Additionally, the discovery of those meanings being socially shaped, shared and created was intended. Exploration of visual social semiotics i.e.: fashion brands in fashion magazine advertisements and how they are 'read', was seen to offer ground for exploring how such images effect the symbolisms, opinions and meanings formed.

Although relatively small, the Greek market was found to have the 'highest proportion of luxury branded items worldwide (Nielsen 2008 as cited in Perry and Kyriakaki 2014) even after the economic crisis. Influenced by the UK and USA (Hatzithomas et al. 2009) through great media exposure, Greek consumers have been found to prefer expensive foreign fashion brands over Greek ones as they are considered to be better in quality (Kamenidoy et al. 2007).

*Independent Researcher, Sweden. 


\section{Literature Review}

\section{Brand Symbolism and Advertising}

Brands have symbolic meanings (Elliot and Leonard 2004), acting as 'codes' (McCraken and Roth 1989) and 'labels', publicly displayed (Feinberg et al. 1992) to create messages (Auty and Elliot 1998) in order to make presences distinguishable (Piamphongsant and Mandhachitara 2008). Through semiotics an understanding of brand symbolism can be accomplished. Valentine (2003) for instance supports the notion of 'brand mirrors', where expressing self-image is possible is encoded in various semiotic 'languages'.

Through 'fashionable' items consumers fulfil social needs (Waide 1987) and consumers signal their status (Dion and Boraz 2017) as visibility of fashion clothing acts as a form of expression (Petrenko 2015). Brands, such as luxury ones, are purchased to intentionally display brand ownership (Husic and Cicic 2009) and 'show off' (Elliot and Leonard 2004) due to their perceived symbolic value (Tynan et al. 2009). 'Louis Vuitton' for instance enables buyers to differentiate themselves (Hume and Mills 2013) as brand status affects purchasing attitudes (Thanh 2012) with brand differentiation affecting the way brands are perceived, i.e.: suitable for different individuals (Jiang 2004). This displays how the unique brand identity and meaning serves fulfilment of social needs.

Brand personality serves a symbolic function (Klink and Athaide 2012) as its characteristics directly influence its relationship with its owner (Fennis and Pruyn 2007) attempted commonly in 'matching' brands to consumers (Cianfrone et al. 2006) and increase brand awareness (Heckler et al. 2014) through advertising images (Meenaghan 1995).

\section{Social Interaction and the 'Self'}

Greater knowledge in marketing research has been found to benefit from symbolic interactionist theory, as it contributes to a greater understanding of the meanings consumers attach (Rahman 2013) to fashion brands. The theory can be applied to marketing research regarding consumer perceptions on fashion brand meaning, achieved through its understanding and approach to social groups and the meanings attached to objects and individuals (Zhang and Kim 2013). Blumer's principle of individuals acting towards items based on their meaning (Oliver 2012), can be related to fashion brand symbolism and the meanings that brands have for individuals. Further, since fashion is an continuing process (Dean et al. 2016) symbolic interactionism was found to be a beneficial approach since via empirical discovery through social interaction, individuals come to realise the real world (Handberg et al. 2015).

The 'self' is believed to be prominent in relation to literature concerning symbolic consumption (Millan and Reynolds 2014), as self-perception is achieved through social interaction with self-values primarily taken from one's family while growing up and being socialised. Meaning is influenced through social interaction (Handberg et al. 2015) and Mead's (1934) ideas can offer a useful basis to gain 
greater insight into how visibility of products is used by individuals in order to communicate something about themselves to others in a symbolic manner (Lee 1990). The 'self' is seen as 'a reflexive process of social interaction' (Callero 2003), considered to play a big role, as images in the media are studied and their effects upon individuals, who often appear to compare themselves to the models in the media (Martin and Peters 2005).

\section{Conceptual Framework}

Figure 1 presents the conceptual thinking, identifying the determinants perceived to shape the meanings, viewpoints and opinions of fashion magazine advertising via a process of consumer interpretation. Magazines provided the opportunity to show participants luxury brands, which are not so commonly seen in other media such as Instagram. The framework derived from advertising and brand research literature.

Figure 1. The Process of Consumer Interpretation of Fashion Brand Magazine Advertising

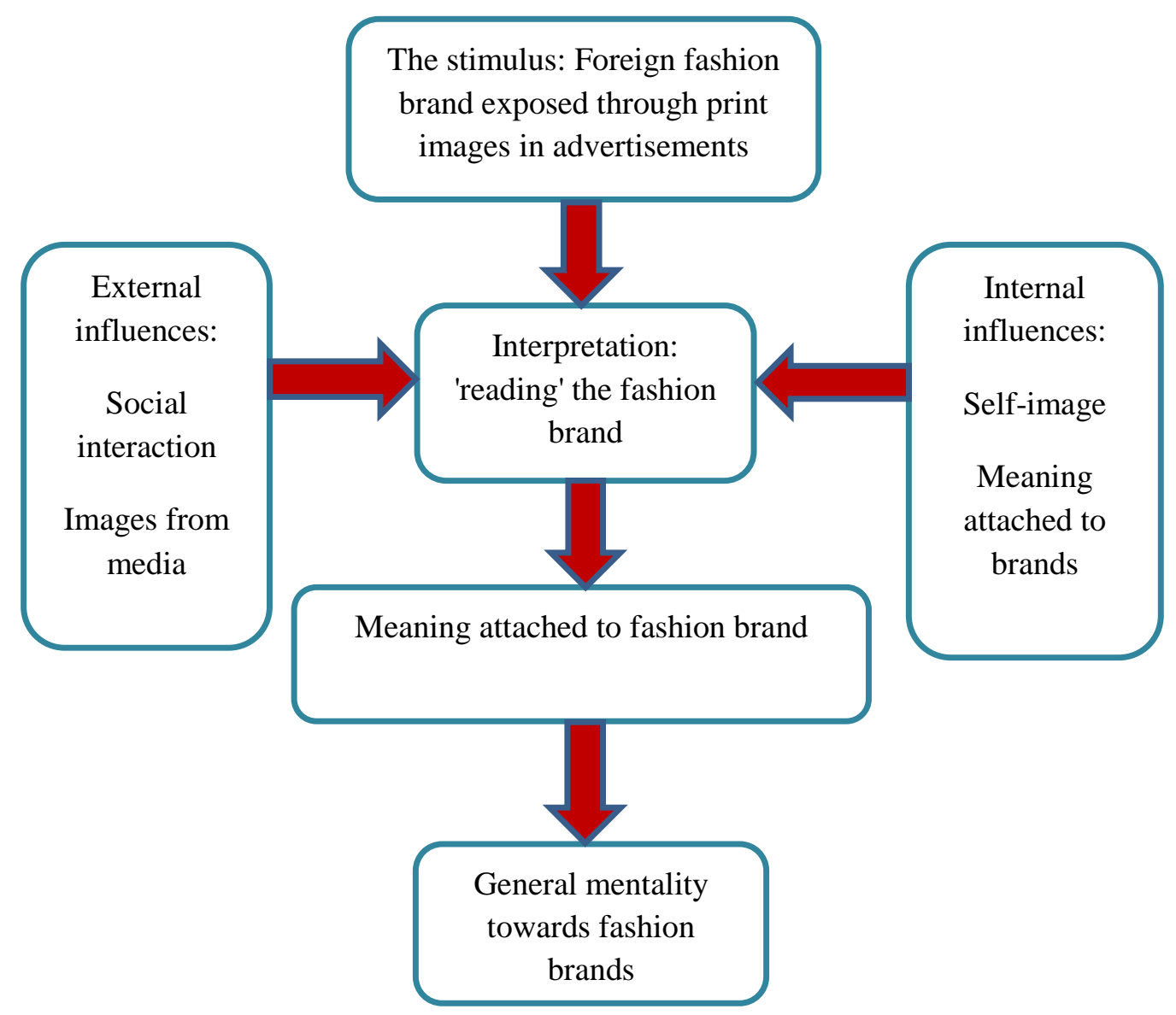




\section{Methodology}

In order to discover in-depth the perceptions, opinions and process involved when 'reading' print magazine advertisements, a qualitative research method was seen as more appropriate. Providing participants with space was crucial in order for them to analyse and go into detail regarding their experiences and relationship to foreign fashion brands and the symbolic meanings they attach to them.

In order to discover how print images are 'read' elaboration was necessary in order to discover print image influences in the attachment of brand meaning. The lack of presupposition adopted in symbolic interactionism assisted the study in terms of the method used, as it was of interest to discover rather than test hypothesis. According to Benzies and Allen (2001),the roots of social interaction in psychology and the approach to truth as 'fluid' by pragmatists, offers the understanding that participants need to be provided with room and comfort to do so, both literally and metaphorically such as the time available and privacy.

The view of individuals experiencing constant adaptation to a social world (Jeon 2004) made it a suitable lens for comprehending and expanding knowledge on Greek women in relation to foreign fashion brands. The approach contributes to the greater understanding of meaning attachment (Rahman 2013) to fashion and the 'world' (Fine 1993) constructed through interaction (Jussim 1991).

\section{Methods}

The research included two phases, interviewing Greek women living in Athens (who came from various cities), different in each phase. A purposive sample was used, of women which the researcher had access to, using a snowball technique when more participants were needed. The Thomas (2006) framework was used to analyse the data, as it assists the 'thick description' in qualitative research while 'making sense' of excessive amounts of data without losing the rich and valuable content. Through close reading and evaluation of text, descriptions of meanings, links and categories can be identified (Thomas 2006).

1) Phase One: 20 semi-structured interviews of $20-40$ year old women. The wide age gap was used in order to identify any patterns related to age.

The phase focused on participant views regarding fashion brands and the symbolic meanings they attach to them and their wearers. They were asked to talk about their relationship with fashion brands and fashion magazines. In the last part of the interview, 20 foreign fashion brands were randomly picked from various Vogue issues (Greek edition). Participants were asked to describe the brands and the women wearing those fashion brands.

Although a plethora of significant findings emerged, it was considered further data would provide an opportunity to illuminate on the influences fashion advertising images within magazines have towards the meanings, views and 
opinions held towards fashion brands. Therefore a Phase Two was seen as appropriate.

2) Phase Two: 10 open-ended interviews, $30-35$ years old. As age in Phase One did not appear to be a determinant in influencing brand perception, meaning or views held by the participants, the mean age from Phase One sample was chosen.

Firstly, participants were given the opportunity to talk about their relationship and views towards fashion brands, the brands they wear and what influences their dress choice.

Secondly, in order to discover more on how print images in advertisements are 'read', and affect brand meaning and symbolism, six advertisements were chosen randomly from Greek editions of Vogue, Elle and Glamour, also randomly picked. The brand name was hidden and participants were asked to talk about the advertisement, how they felt looking at it, guess the brand and item may be advertised and how they would describe it. When participants felt they had nothing more to say about the image, the brand name was revealed and participants had a chance to talk about their views on the advertisements and whether they had changed after knowing the brand.

\section{Findings}

The close study of the transcripts demonstrated patterns forming in a quite 'vivid' manner where the frequency of common responses resulted in the identification of key themes and their association to self, meaning and interaction.

Self, meaning and interaction, important principles in symbolic interactionism (Mead 1934) were found highly relevant to the research, acting as 'pillars', accommodating the key themes identified. Table 3 presents the pillars and key themes relevant to them, all interrelated to each other.

Table 3. Key Themes and the Three Pillars

\begin{tabular}{|l|c|c|c|}
\hline \multirow{2}{*}{ Key theme } & \multicolumn{3}{|c|}{ Pillars } \\
\cline { 2 - 4 } & Self & Meaning & Social interaction \\
\hline $\begin{array}{l}\text { Brands as symbols of self and } \\
\text { socioeconomic status }\end{array}$ & $\mathrm{X}$ & $\mathrm{X}$ & $\mathrm{X}$ \\
\hline Body image and weight & $\mathrm{X}$ & $\mathrm{X}$ & $\mathrm{X}$ \\
\hline $\begin{array}{l}\text { Understanding of the term 'brand' and its } \\
\text { role in projection }\end{array}$ & $\mathrm{X}$ & $\mathrm{X}$ & $\mathrm{X}$ \\
\hline $\begin{array}{l}\text { Shared brand symbolism and brand } \\
\text { copies }\end{array}$ & & $\mathrm{X}$ & $\mathrm{X}$ \\
\hline Shared viewpoints & $\mathrm{X}$ & $\mathrm{X}$ \\
\hline $\begin{array}{l}\text { Advertising as a means of brand } \\
\text { communication and its influences }\end{array}$ & $\mathrm{X}$ & $\mathrm{X}$ & $\mathrm{X}$ \\
\hline $\begin{array}{l}\text { Shared brand meaning, categorisation } \\
\text { and coding }\end{array}$ & & & $\mathrm{X}$ \\
\hline Style influences & & & \\
\hline
\end{tabular}




\section{The Three Pillars}

\section{'Self'}

'Self' was found to be important as self-image plays a big part in the way fashion brands and their advertisements are understood and evaluated. The 'self' is important in how Greek women understand and position themselves and others within their social group. The 'self' can be associated to how fashion advertisements are 'read', related to studies on the 'accepted' or 'ideal', promoted by advertising. Participants tended to compare themselves to what they thought they should look like in order to be able to wear fashionable clothes like the models in the advertisements, expressing weight to be a key determinant in their dress style.

Symbolic interactionist ideas on the social construction of reality are related in regards to how participants perceived their own and other women's bodies, influenced by fashion advertising images.

\section{Meaning}

A shared understanding was displayed in the definition of 'brand', interpreted to mean expensive, known and/or luxury, with certain brands attached to specific symbolic meanings, overall linked to higher socio-economic class. Brand meaning also differs according to the brand, with brand symbolism appearing an important determinant when shopping, as brands are linked to certain symbolic meanings, overall linked to higher socioeconomic status.

\section{$\underline{\text { Interaction }}$}

Shared viewpoints are born through social interaction, interaction with print images in advertisements and interaction with fashion brands. A rich amount of data emerged in regards to the role of interaction in sharing a 'reality' related to brand meanings, categorisation and coding of fashion brands and their wearers.

Advertising acts as a means of communication influencing style equally significant to the influence of social 'norms', concepts of the 'accepted' and 'appropriateness'. A command of social conduct and social standards exist in terms of the 'acceptable' or 'appropriate' way to dress according to the occasion.

\section{The Key Themes}

\section{Brands as Symbols of Self and Socioeconomic Status}

A sense of social fulfilment is gained through fashion brands, suggesting brands act as social tools, offering or inferring social status. Specific symbolic meanings are attached to specific fashion brands commonly associating specific brands to certain individuals. Brands are considered to reflect the socioeconomic status or profession, e.g.: 'X' brand for a doctor, lawyer and 'upper class' supporting 
the notion of consumption being a result of status or means to portray status (O'Cass and Frost 2002).

Luxury or expensive brands were expressed to display 'good taste' or 'superiority' in comparison to cheaper clothes like 'Zara' as 'you get what you pay for' with a tendency in believing such brands influence employment prospects:

'Instantly the other person looks and says 'he has money' and it influences them a lot'.

'Brands' were commonly seen as attractive or tasteful, while non-branded items were not. Foreign fashion brands were considered to have better quality than Greek ones with an apparent shared view of certain fashion brands. 'Louis Vuitton' for instance was frequently mentioned to refer to an expensive, quality brand and 'Chanel' thought to be worn by elegant women.

Shared and common viewpoints suggest social interaction influences meaning creation and attachment to brands, displayed in the common references of how others see brands and how society has taught them to understand fashion brands. Although women wearing fashion brands were seen as 'show-offs', participants acknowledged they do so in order to project a certain image and gain status.

Dress style for different occasions might hold implications for 'acceptable' spending on fashion items as certain brands were perceived suitable for specific social situations:

'I try to dress youthfully on the one hand but appropriately for each occasion I attend, where I am, with whom'.

Although no specific brands were mentioned to be associated with lower socio-economic classes, cheaper fashion brands were not mentioned when talking about 'brands' and socio-economic status:

'You can't always follow fashion and when you aren't in that upper, higher class, and are lower to middle, you step back'.

Specific language and words were used to attach meanings to brands and connotations of words emerged as a way of sharing meaning in relation to fashion. A tendency to speak as outsiders was apparent when commenting on fashion trends, excluding themselves as being affected.

\section{Body Image and Weight}

Weight appeared to be a big issue for Greek women, determining dress choice, style and self-value in terms of size, rather than health:

'when I lose weight it (dress style) does change. I feel more comfortable, wear more colours, I may buy a dress, a skirt, that I think may suit me, while when I'm heavier, I don't feel like shopping'. 
'A piece of clothing cannot be worn by someone who's $50 \mathrm{~kg}$ and another whose 90kg' [Interviewer]: Why? 'It loses its beauty'.

Advertising was expressed to promote 'role models' where Greek women try to look like the models and overall views were overwhelmingly negative. Occasionally, the wider social impacts were mentioned, supporting shops sell clothes for slimmer women, of an 'accepted' style promoted by the fashion industry. The fashion industry and advertisements were seen to have negative effects as:

'It doesn't take into account the average Greek woman because the average Greek woman isn't $1.90 \mathrm{~cm}$ and $45 \mathrm{~kg}$ - no way!

A 'Replay' advertisement (Phase Two) displayed how weight was expressed in many different ways but all related to the model's figure comparing it to theirs. It is demonstrated at this point, how fashion advertisement images can make women feel self-conscious as models appeared to prompt participants' selfreflection.

Participants raised the issue of women dwelling on the possible negative aspects of her figure, weight or size if her perception of her body shape fails to resemble the models.

Participants believed the advertisement attempted to create links between the product and the image of the wearer:

'Put on these jeans and look like that'.

suggesting the intended message aimed at creating a desire to try to look like the model linking fashion items and female identity (concept of 'femininity'):

'because the jeans are skinny, they bring out femininity' (Participant10).

\section{'Brand' and Its Role in Projection}

Language plays an important part, displayed in how 'brand' has a specific, shared meaning, referring to 'eponyma' clothes, (known, expensive or luxury brands) with only 2 participants asking for clarification of what is meant by brand when asked. The findings support the relevance of symbolic interactionism by the similar and common use of the term, displaying the importance of language and how it is shared. It has been displayed that language is important in effective communication within social groups and references to certain brands reinforced the meaning of the term. Brands were seen to act as social tools used to 'show off' and 'project' with 'Louis Vuitton' frequently mentioned as a brand purchased with the intention to stand out within the social group. Brand ownership in general was identified to infer status or success in responses such as: 
'Inside me, I know it doesn't mean anything, but we all want to have a known brand in our wardrobe'.

Such responses suggest internal psychological conflicts within the participant as although admitting 'inside' her the item does not mean anything, at the same time she desires a known brand in her collection, a view clashing with a previous response of brands bought only with a purpose to 'get noticed'.

Brands act as social tools purely for social or psychological reasons, perceived to be purchased for social projection. The importance of brand symbolism was highlighted frequently, relating to the brand's utility and functional value. Greek women understand others based on their brand choices as fashion brands act as markers of the wearer's socioeconomic status. A tendency exists in perceiving higher socioeconomic status positive and aspirational with fashion brands acting as an assessment tool in the 'reading' of the wearer's socioeconomic status.

A fashion brand can be a force, strong enough, to create conflict between personal feelings and consumption patterns and wearing brands was expressed to be a result of being:

'placed in our minds that we'll look better, be better'.

Branded items were implied to have meanings to others if they generate positive or admirable attention with similar sentiments associating fashion brands and status and brands being status symbols. Women purchasing brands they could not afford, were perceived 'pretentious', aiming at displaying a certain economic status unreflective of their current status.

\section{$\underline{\text { Shared Brand Symbolism }}$}

Meanings and symbolism are attached to fashion brands with the belief the brand rather than the actual product sells, displayed particularly when referring to handbags. Brand visibility was considered important as brands act as markers of status, holding specific, strong, symbolic meaning.

\section{'If there was no label on the bag they would never buy it'.}

This was most vividly displayed in the shared understanding of brand meaning and symbolism of brand copies were very strong views were expressed on what fake brands represent to them, commonly using negative terms and attitudes towards their wearers. Even in cases the copy was identical or unnoticeable to the original brand, it was perceived to relate to lower status and taste, contrary to what original brands displayed. Wearing a 'fake' was seen unacceptable even if the wearer belonged to the socioeconomic group initially thought to wear the original.

Wearing fakes was partly objected to as it confused 'reading' the wearer's social status. A copy was seen incapable of living up to the associations of genuine brands ('quality' and 'good'). Wearing them was seen as an 'illegitimate' way 
through which wearers place themselves on specific social categories they did not belong to, a pretentious attitude and attempt to appear something unreflective of reality. Wearers were perceived as 'fake', even 'impostors', creating misconceptions and projecting inauthentic images of their socioeconomic status (associated to Ryan, Eisend and Schuchert-Guler 2006).

Complex views on the relationship between fashion style and brands appeared as participants expressed individuals do not need to spend a lot of money to dress smartly (and were indifferent to spending a lot of money to wear brands) but would not buy a copy. Copies and their wearers were attached to negative terms such as 'fake' and genuine fashion brands were attached to positive symbolic meanings and chosen to wear on special occasions. Participants often expressed how they would be 'afraid' to be discovered to wear fakes by others, more than the bad quality of the copy clearly displaying the importance of projection in social:

'It would bother me if they told me. Of course, if I had bought it, I would be aware of it, but still I would mind... so I avoid doing so'.

The participant was more worried of 'getting caught' wearing copies rather than wearing them displaying the importance of interaction regarding fashion brands.

Overall, social interaction was discovered to be important for the 'self' and the way Greek women understand themselves through it:

'A copy it will show'... visually and ...ok...in my mind.

Even if it doesn't show I will know it's a copy'.

Even when others could not tell, in her mind, copies represented something quite negative, suggesting deeper issues to those of quality. Such issues appeared to originate from the participants' environment with certain views as a result of social interaction, which might reflect how beliefs have been shaped by others:

'If I decide to buy something, e.g.: 'Louis Vuitton', I'll buy the original.

Yes, I'll spend half my salary on it but, if not, I'm not going to buy something fake! I don't want to show off something that isn't authentic'.

Issues around authenticity and the 'self' were discovered by the frequent use of 'show off' proposing an intentional attempt of status display, implying a conscious process of self-projection. Although 'show off' was used in a negative tone when speaking of others, a tendency was apparent in using the same term to explain the reasons behind purchasing fashion brands themselves, displaying double standards. 'Showing off', displayed high relevance in relation to projection, even though participants often denied their desire to 'show off' themselves. This was contradictory to their apparent consumption and views towards fashion brands, linked to beliefs of fashion brands able to make statements. Genuine brands are important in projecting status with purchasing motivated solely in displaying possessions to others. 
Although copies were seen as an attempt to appear something unreflective, participants failed to realise (or acknowledge) spending money they did not have on a item, does indeed display the same behaviour they criticise, as the item is not truly 'affordable' to them. They therefore act in a similar manner to the one they criticise as 'fake', attempting to appear something unreflective. When the participant above was probed, she admitted she was doing so, expanding:

'But the person seeing you doesn't know you have spent half your salary'.

suggesting a greater interest in how Greek women project themselves to others than being true to their personal values (e.g.: being a fake is negative).

\section{$\underline{\text { Shared Viewpoints }}$}

Shared viewpoints and understanding of 'reality' exist, regarding fashion brands and their worth with a general mentality concerning brands and their wearers. The frequency of similar, identical or synonymous terms in responses revealed a specific mentality towards fashion brands and a shared interpretation system used in 'filtering' brands. This was apparent when describing women who might wear different brands (Phase One). 'Gucci' and 'Armani' for example, displayed high levels of consensus in the descriptors attached to them, suggesting shared thinking, language and strength in brand association and meaning.

Media appeared to have a strong influence although perceived by participants to have only a general one. They failed to realise (or admit) the level to which they were affected, suggesting they could be affected subconsciously, failing to realise they belong to the group they criticise. Meanings are attached to advertisements through the use of the same language often using specific vocabulary, displayed in 'good' or 'nice' used in a similar manner when referring to brands. These terms were interpreted in the same way, displaying common attitudes e.g.: frequently using 'psonio' (similar to a show-off).

Common language supports the idea of language being a form of communication in social interaction, responsible for creating definitions and understanding the 'self', others and objects. This was apparent by the descriptors used and attached to fashion brands and the vivid similarities identified in views relating to brand wearers.

Socially-shared symbolisms of fashion brands and the use of 'fashionable' items in order to fulfil social needs were discovered as brands and wearers were labelled and categorised in a specific manner. They expressed to do this on a conscious level as wearing ' $\mathrm{X}$ ' fashion brand is intentionally chosen to project something to others. Brands were perceived to act as symbols, providing hints on the wearer's socioeconomic status, associating fashion brands to wealth.

\section{$\underline{\text { Advertising as a Means of Brand Communication and Its Influences }}$}

Fashion advertising influences brand choice and the models within them, were seen to make individuals crave the clothes they wear and promote certain 
lifestyles and body shapes. Participants acknowledged that advertising has negative effects as it brainwashes, but at the same time expressed fashion brands are important to Greek women, although they themselves were not keen on fashion brands.

Participants expressed the Greek culture and society to be filled with individuals obsessed with fashion brands as it is an important part in a Greek woman's life. Contradictions were highly noticeable throughout, as the importance of brands in the participants' life displayed in their attitudes, appeared to be the same as those they criticised. This was commonly displayed in the participants' references to women wearing brands as: 'psonia' and perceiving brands negatively, but when a participant was asked about 'Burberry' (Phase One) for instance, she smiled, softened the tone of her voice replying: 'my favourite'. This suggests ability to distinguish and differentiate between brands and could be argued that brand knowledge is required in order to have a favourite brand.

Phase Two offered a deeper understanding on the 'reading' of fashion brands, revealing the common use of words when describing advertisements. Even when there was a lack of overall consensus, there was a visible level of agreement in connotations. In a 'Monsoon' advertisement used, participants overall failed to understanding what brand was being advertised (even those who had purchased it in the past), an issue regarding effectiveness levels in the communication between brands and consumers. The shared views expressed towards the brands and advertisement, were commonly negative for similar reasons, with the advertisement commonly seen unsuitable. This displayed a faulty communication process between the brand and the consumer:

'Don't think it is a brand for the Greek audience...,

... 'the colours are not bright'.

Participants failed to match the advertisement to the fashion brand image with confusion towards what was being advertised.

A 'Miss Sixty' advertisement, also displayed shared perceptions quite vividly, with high levels of positive feedback. The brand was commonly described as: 'youthful' with high levels of awareness and the advertisement appeared to effectively communicate with the consumer through the apparent shared views of participants when guessing correctly what was being advertised.

Other advertisements, such as 'UGG' displayed a difficulty in guessing the price range of the item advertised, commonly expressed price could range from very cheap to very expensive. Only upon seeing the brand name participants were able to make a guess on the price displaying how an item or image alone do not have a symbolic meaning and only when the brand is known an attempt in attaching a price can be made. A tendency was displayed in how shared views regarding pricing cannot be effectively provided by the advertisement alone, proposing brands in advertisements are 'read' in combination to participants processing brand names, symbolism and meaning, and their own experiences together. All of these factors serve different purposes but work together when 'reading' the brand, resulting in the formation of brand perceptions which 
influence the level of effectiveness in brand communication regarding consumption choice.

A 'Replay' jeans advertisement, also displayed a failure or mismatch of brands as participants failed to identify the brand correctly. All of the participants replied instinctively, almost reflex-like 'Diesel' as soon as the advertisement was presented. This displayed that participants associate the image to 'Diesel' without offering any reason as to why. Upon revealing the brand, participants expressed that all jeans' brands are the same, without clarifying their immediate response. This raises issues of brand differentiation and level of difficulty in distinguishing between brands of certain fashion items.

Participants commonly stated they did not particularly purchase brands although they appeared to have exceptional high levels of brand awareness considering brands they knew to be of greater quality to those they did not. Specific advertisement images were linked to specific lifestyles and views towards wearers projecting status through brands, seemed to influence advertisement interpretation. A 'Louis Vuitton' advertisement displayed how views appeared to exclusively reflect the 'reading' of fashion brands as tools for projecting socioeconomic status. This was due to the essence of luxury and wealth expressed to be experienced and the relevance of self in interpreting the advertisement:

it refers to the type of kind of rich women the type...

rich more high society...

...refers to a really specific audience, a classic rich woman

from the suburbs'.

The advertisement was perceived to belong to a 'good' brand (clarifying 'good' as expensive and of high quality). When guessing the brand, cases such as 'Chanel' were mentioned displaying a categorisation process where brands are grouped together into similar categories. 'Ralph Lauren' for example, was also described and discussed in the same manner and context and categorized similarly to 'Louis Vuitton' seen as: 'classy', 'elegant' and 'sophisticated'. This displayed shared views and opinions towards the symbolic meanings of certain brands and their advertisements as even when failing to guess correctly, the 'Ralph Lauren' advertisement was expressed to not belong to a brand like 'Replay' but to a fashion house.

Although advertisements were perceived to 'brainwash', the images within them were taken seriously and while fashion media exposes images of thin women, participants did not seem to relate how they could be influenced. Instead, they distanced themselves and spoke of other women being affected although compared themselves to the models.

Overall exposure to advertisements of consumable and disposable goods had a bigger influence, e.g.: make-up, as it was seen more easily accessible compared to clothes (in effort and affordability). Power of advertising over purchasing decisions was displayed as Greek women are open to persuasion from print advertising as it is perceived to be more persuasive in making them go and see the product advertised, as it often offers more product information. Participants 
admitted to purchasing or going to see an item after exposed to its advertisement at some point:

'I see a new foundation 'L'Oréal' has brought out, and I'll say, oh, this according to its presentation and projection covers my needs so let's go and buy it'....

Media influences fashion brand recognition, subconsciously in some instances, as it was clearly reported that brand advertising influences consumers:

'placing it in my head as a known brand, so I recognise it when...

not all brands but some I can recognise, let's say, with my eyes closed by seeing an item or logo or just a shape...or a colour, so it refers me to the brand..'

References of: 'good' and 'bad' in advertising, brings forward issues on perceptions regarding the acceptability or appropriateness of products which are perceived through advertising.

\section{Shared Brand Meaning, Categorisation and Coding}

Attachment of symbolic meaning to brands and brand coding are inter-linked. 'Coding' is a system, resulting from the shared views held towards the meanings of the term 'brand' and the common meanings attached to fashion brands. Codes are 'labels' placed upon brands and wearers, e.g.: 'elegant'. Through coding, effective communication is possible in interaction providing a clear, shared understanding and use of terminology deriving from the language and context used when referring to brands.

The shared views, perceptions, understanding and identification Greek women have of others when wearing specific fashion brands, reflect how the coding system functions and emerges. This system is used to differentiate between the symbolic meanings of fashion brands and their wearers, and effectively communicate when interacting as effective interaction is an outcome of shared language associated with fashion brand meaning.

The 'codes' serve various purposes such as facilitate the effective communication and inform why Greek women use a categorisation process. This became clear in how 'age' slightly affects brand awareness (a couple of cases) and does not appear to have any specific influence on perception towards brands or the descriptors attached to them. Identical or synonymous terms were used to describe specific fashion brands and the fashion industry, commonly linking high price to quality. Once again, participants contradicted themselves:

'by wearing them women have self-confidence to approach someone or could be pretentious'... 
'....the older I get, the more I want to buy something good if I can' ('good' meaning expensive).

Strong views and obvious knowledge of fashion brands were displayed further, as participants (Phase One) were instantly able to articulate opinions about them, with few exceptions. Although the 20 brands used were foreign, brand awareness levels were so high, some were commonly thought to be Greek. Voicing perceptions was effortless, displayed in the attachment of symbolic meaning to fashion brands and the 'coding process' shared which leads to brands and wearers being categorised.

Coding portrays a shared 'reality' through which mutual understanding is developed and acts as a means of communication in brand and wearer categorisation, facilitated by the 'codes' created. Wearers were categorised into different typologies and there was a tendency to categorize brands by various criteria, as references to specific brands (without being asked) were offered as examples of specific situations.

Certain social situations and surroundings were considered factors in certain brands being the 'norm' for everyday use, as environment in upbringing or work was seen to influence individuals. Reasons for wearing brands were connected to different types of women, age groups and socio-economic status:

'in high class it is compulsory (to wear foreign brands), in middle class they may like them

and in the lower class because they want to project'.

Women wearing brands were perceived to have 'economic flexibility', placed in a different group to non-brand wearers with specific symbolisms attached to individuals wearing specific brands, e.g.: 'Burberry' for instance was commonly seen as: 'elegant'.

Brands tended to be grouped in relation to: their target groups, prestige and socioeconomic status, sex appeal and femininity versus 'conservative' and masculine. Description of different brands in a similar manner, suggested participants placed them under the same category e.g.: ' $X$ ' brand is like ' $Y$ ' brand, 'they are in the same category'.

\section{$\underline{\text { Style Influences }}$}

Style was talked about in two ways: as a creation and projection of a personalised style and the way they dressed. Style was expressed to be the wearing of clothes which suited them and felt comfortable in, physically and mentally. Although friends, family and work were expressed to not influence clothing choice, participants acknowledged they could not dress as they wished at work or special events when asked. Appropriateness of time and a place act as determinants in dress style, with an apparent understanding in what is commonly 'appropriate' and acceptable in certain situations. This is an indicator of how although Greek women support to not be influenced, their dress style is highly 
influenced by society and social conventions, peer groups, and advertising which did indeed appear to influence dress style did not solely depend on personal taste or personality.

Weight and body image was also displayed to influence dress style but could not be explored in depth due to acknowledged potential sensitive ethical issues. Clothes were through to look better on thin bodies and weight 'ideals' and 'norms' appeared to be important when dressing. Weight determined most of the participants' purchasing choices which depended on what 'suits' them, failing to define the criteria in deciding this:

'I have been influenced by pregnancy, it changed my body a lot and can't yet control it. I can't find the rhythms I once had of my body and this annoys me a little and because of that I don't want to see it in the mirror and therefore I wear longer clothes, more baggy top'.

\section{Discussion}

As a lens, symbolic interactionism assisted rather than 'shaped' the findings. The research can be seen to build on Kamenidou et al. (2007) and towards Greek women's understanding of foreign fashion brands and the value they place on them while gaining a more in-depth knowledge of opinions held and the effectiveness of fashion advertising towards those views.

The findings can be seen to be highly relevant to Goffman's (1959) notions of 'acceptable' and 'norm' in dressing appropriately to according social situations. The 'coding' and categorising process emerging through the labelling of brands and wearers in regards to how Greek women 'presented' themselves in different social situations can be seen of relevance and built upon Goffman's notions.

A greater and more detailed understanding was gained regarding the process consumers go through in order to interpret images exposed to in print advertisements within fashion magazines e.g.: the image and brand name is needed to guess the price of the item. The interviews provided clues to the existence of a process far more complex and socially-defined than a simple sense-making of brands initially considered. Figure 2 presents the proposed process individuals go through emerging from the findings.

\section{An Explanation of Figure 2}

Figure 2 suggests the influences and the process Greek women go through to form the mind-sets, views, meanings and opinions towards foreign fashion brands. Each 'stage' is explained next. 
Figure 2. The Process of Consumer Interpretation of Fashion Brand Magazine Adverting

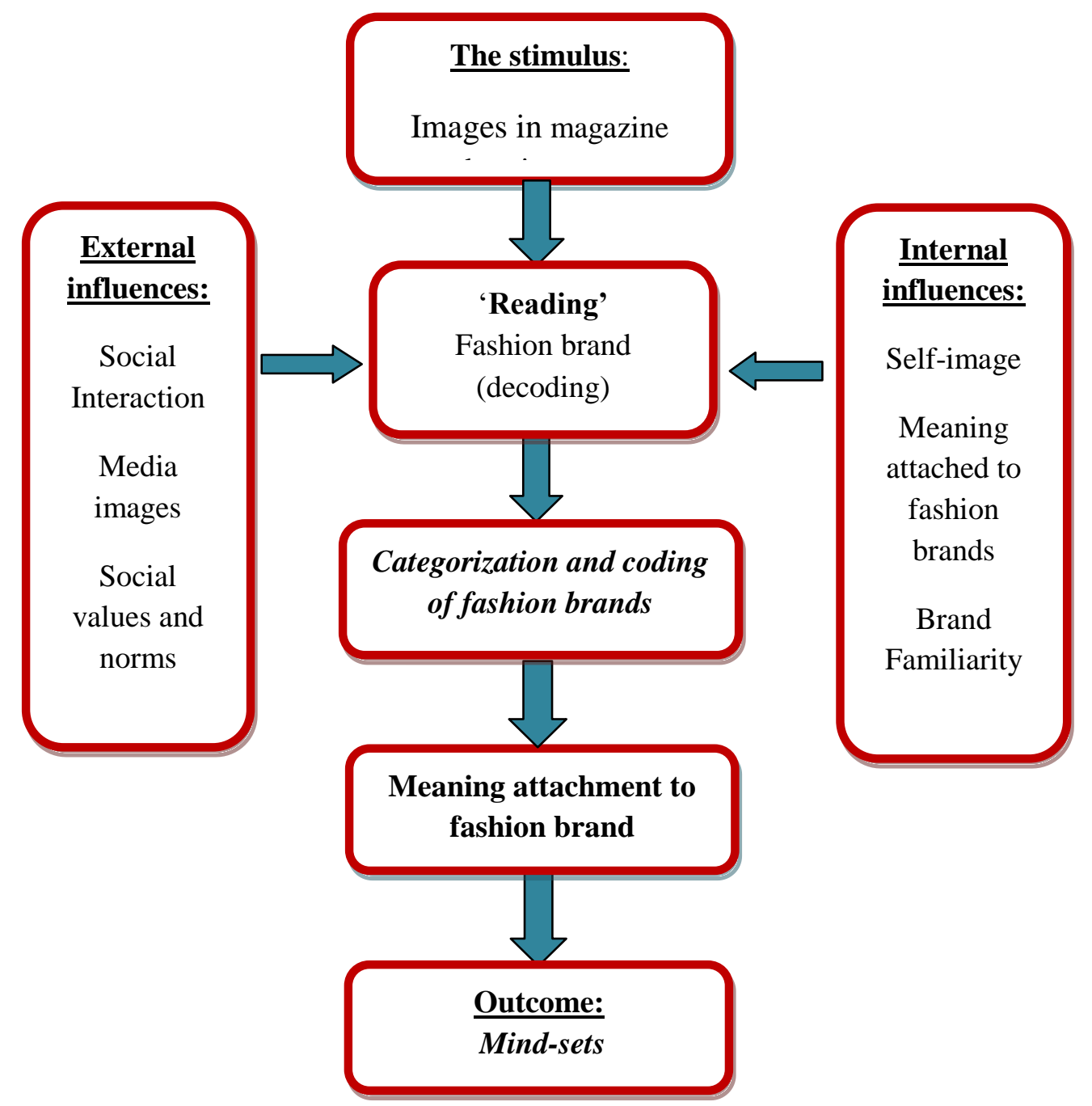

\section{The Stimulus}

The stimulus does not simply create brand awareness or acts as a means of information. It is linked to the reader's familiarity levels with an advertisement of specific, named brands and brands categorised as 'similar' within a choice set of brands.

Additionally, it influences individuals through the images it projects, acting as a 'code' transmitter. Images act in various ways through which brands are communicated offering information such as brand identity. The stimulus influences at a similar level to 'internal' and 'external' influences but is placed separately, as it follows marketing strategies and is part of a communication process planned between the product and the consumer. It attempts effective communication regardless or independent of the external and internal influences being a separate type of influence as it is not socially or individually-controlled. 
Although the stimulus could be debated to be an external influence, it is not socially created, as the outcome is, and in the context of the research, the stimulus is perceived to be a means of communication Greek women are exposed to.

\section{The Influences}

The influences are considered instrumental in how fashion brands are 'read', acting as the first stage participants go through/ face. They inform individuals by exposing them to images where messages within fashion brands and media are received. Both sets of influences have an impact, following initial exposure to fashion brands, shaping the 'reading' of the stimulus. The influences are the starting point, where all of the information is achieved. Whether this is created through the social group, self-perception or experience, they are all influential in their own unique way and combined, affect the way fashion brands are 'read' or understood.

\section{External Influences}

Social interaction and interaction with print images influence how fashion brands are understood and 'read' through advertising practices. Through social interaction, individuals achieve a sense of acceptability of style and fashion brands as well as concepts of 'norm', 'ideal'. Shared reality in general is discovered regarding fashion brands, shaping shared understanding.

Understanding such social norms impacts fashion brand perception while the stimulus shapes norms and ideals, in the same way those are created through interaction. The social 'norms' created through interaction and the 'stimulus' are equally important, and although the processes differ, their effects are equally significant as the stimulus has a relatively strong influence. This is displayed particularly in weight and body shape issues, revealed by the thin 'ideal' in female body shape, considered to be promoted by fashion advertising which significantly impacts what is considered attractive or beautiful, in relation to this medium.

\section{Internal Influences}

Internal influences displayed to be determinants in self-image, meaning and familiarity. They were considered internal influences as they emerged from selfperception, as Greek women evaluate themselves by comparing what they look like to what they 'should' look like. They value themselves in terms of their selfimage and its 'acceptability' within their social group (e.g.: weight, size and body image). Although acceptability of the social group is considered an external influence, self-image was perceived in relation to how Greek women see themselves and how that influences a shared 'reality' in their society.

Participants distanced themselves from their social group supporting their self-image not being influenced by external factors, although shown they were indeed influenced and not subjective in how they 'see' themselves and their selfimage. Internal factors influence Greek women when attaching meanings to 
fashion brands but are less significant than external influences in regards to the aim of the research. Weight and body image play a great role in influencing views in terms of dressing up and media influences which stem from fashion advertisements in magazines.

The way their body looks is of greater importance to Greek women than the suitability of an item in regards to their age, as weight and body image affects dress style and purchasing decisions. They wear certain clothes only when slimmer, as certain types of clothes were thought to look better on 'thin' bodies with a common understanding of clothes looking better and being more suitable for thin rather than fit bodies. This can be related to symbolic interactionism and the shared meanings and symbolism which are created through social interaction while constructing concepts of the accepted, 'ideal' and attractive body type. Also, self-description can be related to how the stimulus and social interaction affects individuals. Self-image is linked to projection and reflection displayed in the notion Greek women have, that in order to be accepted or desired within their social group, a certain body type or image is mandatory, including societal acceptance.

Advertising alone displayed to be more influential in reinforcing existing brand knowledge rather than create knowledge for inexperienced brands, apparent when participants openly compared and contrasted advertisements (Phase Two) to their experiences and familiarity with the named brands, with a tendency to 'reject' advertisements when 'mismatching' them to the actual brand.

\section{'Reading' the Fashion Brand}

Individuals 'read' fashion brands and this stage acts as a way of decoding information offered in the stimulus. The influences and images contribute to how individuals make sense of brands and decode the information exposed to, in order to form views, opinions and meanings. Readers interpret information about fashion brands which can be seen relevant to literature on advertising creating 'values' (e.g.: Meenaghan 1995). This is seen 'in action' in the reactions to the advertisements (Phase Two) as participants offered the clues they used when attempting to guess the advertised brand, its projected message and suitability to them, revealing how cultural meanings stem from the individual's world (Elliot and Wattanasuwan 1998) and how consumers 'socialisation' (Petit and Zakon 1962) through this.

\section{Meaning Attachment}

The stimulus and influences contribute in creating meanings, developed in the process of understanding fashion brands and the ways social meaning is attached to them. The influences affect the process in various ways and through meaning attachment, Greek women understand a brand's social status, power and social utility. This can be linked to symbolic interactionism and studies on the symbolic meanings of brands and the fulfilment of symbolic needs (Bhat and Reddy 1998). Creation of brand identity is not carried out here, but is completed in the stimulus, 
shaping brand identity and the external influences affecting identity. Interaction creates shared understanding of foreign fashion brands and their meaning. Consistency in shared meanings exists in the general meaning of fashion brands and in very specific ideas and mentality of specific brands (linked to Piamphongsant and Mandhachitara 2008). Brands act as a non-verbal language, through which individuals can be understood and feel part of a society while fulfilling social needs (Waide 1987).

With respect to the specific symbolic meanings of foreign fashion brands, consumers go through a stage creating 'codes' in order to categorise fashion brands according to their meaning.

\section{Categorisation and Coding}

Fashion brands are categorised in relation to the symbolic meaning attached to them, considered in relation to the understanding or perceptions of them. Certain words were adopted in categorising while discussing fashion brands. The words were used as 'codes' in communication with brands and wearers 'labelled' or discriminated against (relevant to Blummer 1969 and Elliot and Leonard 2004). This can build on a greater understanding on the symbolic meanings attached to brands and their use as 'social tools' as fashion brands are categorised in terms of 'value' and 'power'. A process which pre-exists, results in the 'coding', categorisation and placement of fashion brands in specific categories depending on various factors.

Coding and categorising appeared to be inter-related, with 'codes' acting as labels of specific symbolic meanings attached to brands, assisting the brands' placement in specific categories. This is commonly done in relation to the brands' suitability to individuals of a specific socioeconomic status and categorisation is carried out by using the same criteria, supporting studies such as Laroche et al. (1986). Fashion brands are seen to be used in order to project (via their symbolic meanings), supporting their role as social tools.

The participants displayed two types of projection: intentional, through which they attempt to show something to others (regardless of it being reflective of current socioeconomic status) and reflective, which enables an understanding of the wearers' socioeconomic status. These findings can relate to Goffman's (1959) views on stereotyping against individuals due to their appearance and dress style to depend on different social situations. Goffman's notion of 'performers', 'moulded and modified to fit into the understanding and expectations of society' (Goffman 1959: 44) can also relate to the shared understanding of fashion brands and their wearers in terms of 'suitability' of self-presentation by occasions by wearing specific brands.

The 'codes' fundamentally represent a brand's unique symbolic meaning, how these meanings are shared, and their use as a key tool in effective communication in social interaction related to Mead's (1934) theory of projection. The findings can strengthen the symbolic interactionist approach in regards to how individuals understand themselves, others and objects (namely fashion brands) through interaction and the creation of symbolisms through language. Fashion 
brand 'coding' proposes the importance of language as a means of non-verbal communication and the shared reality within the coding process, suggests a need in labelling both fashion brands and their wearer in explicit terms.

Certain fashion brands were attached to certain meaning which others were not, which supports the idea of a categorisation process of fashion brands and wearers. Most significantly, the relation of the findings to symbolic interactionism are discovered, displayed in the attachment of symbolisms to fashion brands lending support to the use of the methodology and methods chosen.

\section{Formation of Viewpoints and Opinions}

The attachment of symbolic meanings to fashion brands leads to a creation of 'codes' acting as a 'labelling' system. This is demonstrated in how Greek women need to label fashion brands and their wearers, in order to make sense of, and position them within their social group. The Labels which act as 'codes', enable efficient communication through shared non-verbal language and use of the same words and context.

The meanings, labels and 'codes' are then used to categorise brands, acting as a component in forming views and opinions towards fashion brands and their wearer which can be related to symbolic interactionist theory of fashion acting as language (Blumer 1969) through which Greek women communicate non-verbally. Additionally, it is vividly demonstrated how symbolic interactionism (as a framework) assists in gaining a wider understanding of the interaction process between consumers and fashion brands in the way labels are attached to fashion brands. Brand differentiation and categorisation are indicators of how Greek women distinguish between fashion brands and label them.

This process occurs in various ways involving a more complex process, including many determinants when categorising and 'coding' due to the meanings attached which result from a complex thinking process, influenced by social interaction and the stimulus. The process exists in the way fashion brands are perceived (of high quality or not) and is also a result of a mutual and common shared symbolic meaning attached to fashion brands.

Categorisation mainly concerns factors such as price, intention to project quality, prestige and suitability to socioeconomic status and profession (e.g. a lawyer needs to dress smartly) relating to Goffman's (1959: 40) identical example. These findings are suggested to build on the idea of dressing 'accordingly' depending on the social situation. Furthermore, categorisation depends on the brands worn, as through them, wearers can be understood, identified, perceived and described. Greek women 'read' both the fashion brands and the wearers (as proposed by Elliot and Leonard 2004 and Kamenidou et al. 2007).

The categorisation process appears to exist due to the stimulus and influences as they impact individuals in various ways. The influences are responsible for individuals' perceptions of fashion brands, contributing to the formation of symbolic meanings of brands and wearers. This is followed by a brand categorisation placement through labelling and coding resulting to the use of 
fashion brands as projection tools. This displays how brands are used to project either intentionally or reflectively by Greek women.

\section{Outcome: Mind-Sets towards Fashion Brands}

This 'stage' is the outcome of the process shown in Figure 2 offering greater knowledge on the overall mentality of Greek women towards foreign fashion brands and the way it is formed. It is a result of the previous 'stages', which are the general views and opinions of Greek women and the shared reality that exists.

A socially-created culture is existent around foreign fashion brands, displayed in the similar mind-set towards them with frequent references to what peers think, suggesting the contribution of social interaction in forming socially shared views. A specific culture is created where a certain mind-set and attitude towards fashion brands exists and the relationships created between individuals and brands, relevant to consumerism and the meanings attached to fashion brands by consumers. Hedonic and symbolic brand consumptions is apparent with 'brand' referring to expensive, known and luxury fashion brands. An understanding of fashion brand meaning is shared related to brand community research (e.g.: Schembri 2009) regarding the building of social and cultural relationships. This is mostly seen relevant in the culture created by Greek women, as it is suggested the culture around fashion brands inevitably affects brand consumption.

Lastly, this 'stage' builds on the Kamenidou et al. (2007) findings in regards to the greater understanding of Greek women in terms of why and how they perceive and feel about foreign fashion brands.

\section{Conclusion}

Overall, the value of the research contributes towards a better understanding of the Greek female consumer in regards to the symbolic meanings she attaches to foreign fashion brands and their wearers, created mostly through social interaction. This is displayed for instance, in how 'brand' is used to refer to expensive, known and luxury fashion items with specific symbolic meanings attached to certain fashion brands. This demonstrates the role of non-verbal language, as brands act as social tools and a means for intentional projection as well as a reflection of the wearer's actual state.

More specifically, the research offers an opportunity to see how the female Greek consumer 'reads' foreign fashion brands through the stimulus and the process they go through in forming a mentality towards them (Figure 2).

Practitioners can benefit as the research also displays how a sociological approach, such as symbolic interactionism, can assist brand research in gathering 'valuable' information via 'thick description'. This can reinforce the more effective way consumers are approached with acknowledgement of consumers needing to be treated more like the complex beings they are than a passive audience open to compliance. 
Moreover, the development of clearer insights into the Greek market which, although apparent to be attracted to luxury brands, has not so far been particularly studied in relation to the overall mentality towards fashion brands. The research has offered a greater understanding of the female Greek consumer and how she 'reads', understands and decodes brands and more significantly, the discovery of an existent shared mind-set or mentality towards foreign fashion brands is understood (Figure 2).

The better understanding of the Greek female consumer's general mentality towards fashion brands and how they are understood (Figure 2), can offer a more effective and improved brand identity strategy in brand building and promotion and inform practitioners in various dimensions in how print advertisements are 'read'. Such knowledge can contribute to a greater understanding of this neglected market as it appears particularly significant in promotional practises and strategic planning.

Key contributions to knowledge are emphasised in relation to how the socioeconomic status and the projection of self in relation to status emerged as a key underpinning factor in fashion consumption. Further, the print images within advertisements emerged as a stimulus which may add to, rather than drive brand awareness, knowledge and perceptions where the 'social' dimension of theories such as self-congruity theory (Sirgy 1986, Jamal and Goode 2001) might be further researched. The wider social values and norms which emerged as a significant influence on the brand communication process and fashion advertising can also contribute to greater knowledge in relation to consumer use and meaning attachment of fashion brands beyond utilitarian purposes as fashion brands serve social situations to matter to the individual's social group.

The specific and common words and terms used and the symbolic meanings attached to fashion brands, are a form of non-verbal communication, through which fashion brands are understood. Fashion brands are associated to wealthy women, of a certain socioeconomic status and even when negative feelings were displayed, a consensus in views was present. Counterfeit products were generally perceived to be of inferior quality to original ones while their wearers were commonly seen as 'fake' and pretentious, attempting to appear something that is unreflective of their socio-economic status.

Greek women's relationship to fashion magazines relates to social factors and social interaction, making further contribution on fashion brand and fashion brand perception research of Greek women. Advertising is perceived to set standards and was displayed to influence purchasing decisions significantly. Further, fashion brand advertisements were seen make Greek women conscious of their bodies with weight being a key determinant for dress style, purchasing decisions and perception of self-image. This provides a greater understanding on how print fashion images are 'read' building on existing research on the effects of images in fashion advertising as participants compared themselves to the models. 


\section{References}

Auty S, Elliot R (1998) Fashion involvement, self- monitoring and the meaning of brands. Journal of Product and Brand Management 7(2): 109-123. Available at https://www. emeraldinsight.com/doi/abs/10.1108/10610429810216874.

Benzies KM, Allen MN (2001) Symbolic interactionism as a theoretical perspective for multiple method research. Journal of Advanced Nursing 33(4): 541-547. Available at: https://onlinelibrary.wiley.com/doi/abs/10.1046/j.1365-2648.2001.01680.x.

Bhat S, Reddy SK (1998) Symbolic and functional positioning of brands. Journal of Consumer Marketing 15(1): 32-43. Available at https://emeraldinsight.com/doi/abs/ $10.1108 / 07363769810202664$.

Blumer H (1969) Fashion: from class differentiation to collective selection. Sociological Quarterly 10(3): 275-291. Available at https://onlinelibrary.wiley. com/doi/abs/10. 1111/j.1533-8525.1969.tb01292.x.

Callero PL (2003) The sociology of self. Annual Review of Sociology 29: 115-133. Available at https://www.annualreviews.org/doi/abs/10.1146/annurev.soc.29.010202. 100057.

Cianfore B, Bennett G, Siders R, Tsuji Y (2006) Virtual advertising and brand awareness. International Journal of Sport Management and Marketing 1(4): 289-310.

Dean D, Arroyo-Gamez RE, Punjaisri K, Pich C (2016) Internal brand co-creation: The experiential brand meaning cycle in higher education. Journal of Business Research 69(8): 3041-3048. Available at https://www.sciencedirect.com/science/article/abs/ pii/S0148296316000321?via\%3Dihub.

Debicka M (2000) Advertising-the art of manipulation. Cultural determinants in effectiveness of advertising, Polish and American cases. In LV Ryan, M Eisend, P Schuchert-Güler (2006) Explaining counterfeit purchases: A review and preview. Academy of Marketing Science Review 12(6): 1-25. Available at https://www.research gate.net/profile/Martin_Eisend/publication/252248476_Explaining_Counterfeit_Purc hases_A_Review_and_Preview/links/0a85e5395b8b8297a9000000/Explaining-Cou nterfeit-Purchases-A-Review-and-Preview.pdf.

Dion D, Borraz S (2017) Managing Status: How Luxury Brands Shape Class Subjectivities in the Service Encounter. Journal of Marketing: 81(5): 67-85. DOI= https://doi.org/ 10.1509/jm.15.0291.

Elliott R, Leonard C (2004) Peer pressure and poverty: Exploring fashion brands and consumption symbolism among children of the 'British poor. Journal of Consumer Behaviour 3(4): 347-359. DOI= https://doi.org/10.1002/cb.

Elliot R, Wattanasuwan K (1998) Brands as symbolic resources for the construction of identity. International Journal of Advertising 17(2): 131-144. Available at https:// www.tandfonline.com/doi/abs/10.1080/02650487.1998.11104712.

Feinberg RA, Mataro L, Burroughs WJ (1992) Clothing and social identity. Clothing and Textile Research Journal 18(1): 18-23. Available at http://journals.sagepub.com/doi/ abs/10.1177/0887302X9201100103.

Fennis BM, Pruyn ATH (2007) You are what you wear: Brand personality influences on consumer impression formation. Journal of Business Research 60(6): 634-639. Available at https://www.sciencedirect.com/science/article/abs/pii/S0148296306002 293.

Fine GA (1993) The sad demise, mysterious disappearance and glorious triumph of symbolic interactionism. Annual Review of Sociology 19: 61-87. Available at https:// www.annualreviews.org/doi/10.1146/annurev.so.19.080193.000425.

Goffman E (1959) The presentation of self in everyday life. NY: Anchor. 
Handberg C, Thorne S, Midtgaaard J, Nielsen CV,Lomborg K (2015) Revisiting symbolic interactionism as a theoretical framework beyond the grounded theory tradition. Qualitative Health Research 25(28): 1023-1032. Available at https://journals.Sage pub.com/doi/abs/10.1177/1049732314554231? journalCode=qhra.

Hatzithomas L, Boutsouki C, Zotos Y (2009) The effects of culture and product type on the use of humor in Greek TV advertising: An application of Speck's humorous message taxonomy, Journal of Current Issues and Research in Advertising 31(1): 4361. Available at https://www.tandfonline.com/doi/abs/10.1080/10641734.2009.10 505256.

Heckler SE, Keller KL, Houston MJ, Avery J (2014) Building brand knowledge structures: Elaboration and interference effects on the processing of sequentially advertised brand benefit claims. Journal of Marketing Communications 20(3): 176-196. Available at https://www.tandfonline.com/doi/abs/10.1080/17544750.2012.660766?src= recsys\&journalCode=rjmc20.

Hume M, Mills M (2013) Uncovering Victoria's Secret. Exploring women's luxury perceptions of intimate apparel and purchasing behavior. Journal of Fashion Marketing and Management 17(4): 460-485. Available at https://www.emeraldinsig ht.com/doi/abs/10.1108/JFMM-03-2013-0020.

Husic M, Cicic M (2009) Luxury consumption factors. Journal of Fashion Marketing and Management 13(2): 231-245. Available at https://emeraldinsight.com/doi/abs/10.11 08/13612020910957734?journalCode=jfmm.

Jeon YH (2004) The application of grounded theory and symbolic interactionism. Scandinavian Journal of Caring Sciences 18(3): 249-256. Available at https://online library.wiley.com/doi/abs/10.1111/j.1471-6712.2004.00287.x.

Jamal A, Goode MMK (2001) Consumers and brands: a study of the impact of self-image congruence on brands preference and satisfaction. Marketing Intelligence and Planning 19(7): 482-492. DOI= https://doi.org/10.1108/0263450011040 8286.

Jiang P (2004) The role of brand name in customization decisions: a search vs experience perspective. Journal of Product \& Brand Management 13(2): 73-83.

Jussim L (1991) Social perception and social reality: A reflection-Construction model. Psychological Review 98(1): 54-73. Available at https://eric.ed.gov/?id=EJ494107.

Kamenidou I, Mylonakis J, Nikolouli K (2007) An exploratory study on the reasons for purchasing imported high fashion apparels. The case of Greece. Journal of Fashion Marketing and Management 11(1): 148-160. DOI= https://doi.org/10.1108/136120 20710734463.

Karanika K, Hogg MK (2010) The interrelationship between desired and undesired selves and consumption: The case of Greek female consumers' experiences. Journal of Marketing Management 26(11-12): 1091-1111. DOI= https://doi.org/10.1080/0267 257X.2010.508979.

Klink RR, Althaide GA (2012) Creating brand personality with brand names. Marketing Letters 23(1): 109-117. DOI= https://doi.org/10.1007/s11002-011-9140-7.

Laroche M, Rosenblatt JA, Manning T (1986) Services used and factors considered important in selecting a bank: an investigation across diverse demographic segments'. International Journal of Bank Marketing 4(1): 35-55. DOI=http://dx.doi.org/10.11 08/eb010771.

Lee DH (1990) Symbolic interactionism: some implications for consumer self-concept and product symbolism research. Advances in Consumer Research 17: 386-393. Available at http://acrwebsite.org/volumes/7037/volumes/v17/NA-17.

Martin MC, Peters CO (2005) Exploring adolescent girls' identification of beauty types through consumer collages, Journal of Fashion Marketing and Management 9(4): 
391-406. Available at https://www.emeraldinsight.com/doi/ abs/10.1108/136120205 10620777.

McCracken GD, Roth VJ (1989) Does clothing have a code? Empirical findings and theoretical implications in the study of clothing as a means of communication. International Journal of Research in Marketing 6(1) 13-33. DOI= https://doi.org/10. 1016/0167-8116(89)90044-X.

Mead H (1934) Mind, Self and Society. Chicago: University of Chicago Press.

Meenaghan T (1995) The role of advertising in brand image development. Journal of Product and Brand Management, 4(4): 23-34. DOI= https://doi.org/10.1108/10610 429510097672.

Millan E, Reynolds J (2014) Self-construals, symbolic and hedonic preferences, and actual purchase behavior. Journal of Retailing and Consumer Services 21(4): 550-560. Available at https://pdfs.semanticscholar.org/282a/c7ccaab 32ee0c0cf1440e348 fdf1c 7251564.pdf.

O' Cass A, Frost H (2002) Status brands: examining the effects of non-product-related brand associations on status and conspicuous consumption. Journal of Product \& Brand Management 11(2): 67-88. DOI= https://doi.org/10.1108/10610420210423 455.

Oliver C (2012) The relationship between symbolic interactionism and interpretive description. Qualitative Health Research 22(3): 409-415. DOI= https://www.ncbi. nlm.nih.gov/pubmed/21876207.

Perry P, Kyriakaki M (2014) The decision making process of luxury fashion retail buyers in Greece. Journal of Fashion Marketing and Management 18(1): 85-106. DOI= https://doi.org/10.1108/JFMM-06-2012-0030.

Petit TA, Zakon A (1962) Advertising and social values. Journal and Marketing 26(4): 15-17. DOI= https://www.jstor.org/stable/1248333.

Petrenko VV (2015) Fashion: The game on social meaning and the cynical strategy of consumption. Procedia- Social and Behavioural Sciences 200: 509-513. DOI=https:// doi.org/10.1016/j.sbspro.2015.08.010.

Piamphongsant T, Mandhachitara R (2008) Psychological antecedents of career women's fashion clothing conformity. Journal of Fashion Marketing and Management 12(4): 438-455. DOI= https://doi.org/10.1108/13612020810906119.

Rahman K (2013) 'Wow! It's Cool!': the meaning of coolness in marketing. Marketing Intelligence \& Planning 31(6): 630-638. DOI= https://doi.org/10.1108/MIP-09-20120094.

Schembri S (2009) Reframing brand experience. The experiential meaning of HarleyDavidson. Journal of Business Research 62(12): 1299-1310. DOI= https://doi.org/ 10.1108/13612020810906119.

Sirgy MJ (1986) Self-Congruity: Toward a Theory of Personality and Cybernetics. New York: Praeger Publishers.

Thomas DR (2006) A general inductive approach for analyzing qualitative evaluation data. American Journal of Evaluation 27(2): 237-246. DOI= https://doi.org/10.11 77\%2F1098214005283748.

Tynan C, Mckechnie S, Chhuon C (2009) Co-creating value for luxury brands. Journal of Business Research 63(11): 1156-1163. Available at https://www.sciencedirect.com/ science/article/abs/pii/S0148296309002793.

Thanh NND (2012) Relationship between brand awareness, perceived quality, trust, value, loyalty and brand equity: A case study of Vinamilk brand in Ho Chi Minh, Vietnam. $A U$-GSB e-journal 5(2): 93-100. Available at http://www.assumptionjournal.au. edu/index.php/AU-GSB/article/view/477. 
Valentine V (2003) Using semiotics to build powerful brands for children. Young Consumers 4(2): 9-16. https://edisciplinas.usp.br/pluginfile.php/3247411/modresour ce/content/1/Zakia_Nadin_1987_Semiotics\%20advertising\%20and\%20marketing.pdf.

Waide $\mathbf{J}$ (1987) The making of self and world in advertising. Journal of Business Ethics 6(2): 73-79.DOI= https://doi.org/10.1007/BF00382020.

Zhang B, Kim JH (2013) Luxury fashion consumption in China: factors affecting attitude and purchase intent. Journal of Retailing and Consumer Services 20(1): 68-79. https:// www.scirp.org/(S(czeh2tfqyw2orz553k1w0r45))/reference/ReferencesPapers.aspx?

ReferenceID $=2182525$. 
